\title{
Trichophagia and Trichobezoar: Case Report
}

\author{
Santos, Tiago ${ }^{\mathrm{a}}{ }_{*}$, Madeira Nuno $^{\mathrm{b}}$, Alcafache João $^{\mathrm{a}}$, Vicente $\mathrm{Carla}^{\mathrm{a}}$, Molinar Gonçalo ${ }^{\mathrm{c}}$ and \\ Noronha Joana ${ }^{c}$
}

${ }^{a}$ Department of Psychiatry and Mental Health, Hospital Infante D. Pedro, Aveiro, Portugal

${ }^{b}$ Psychiatry Clinic, Coimbra University Hospital, Coimbra, Portugal

${ }^{c}$ Department of General Surgery, Infante D. Pedro Hospital, Aveiro, Portugal

\begin{abstract}
Objective: Trichobezoar consists of a compact mass of hair occupying the gastric cavity to a various extent. When the trichobezoar extends past the duodenum it is better referred to as Rapunzel Syndrome. Although trichobezoars are well described in terms of surgical diagnostic and procedure, there are only but very scarce reports on psychiatric literature, usually associated with trichotillomania. The authors present a clinical case of trichobezoar and discuss the most relevant aspects concerning this entity.

Methods: Presentation of psychiatric and surgical data concerning the case report. Previously reported cases are also mentioned.

Results: Report of a 27-year-old female patient with a trichobezoar submitted to surgical removal, with a prior intervention 4 years before also due to trichobezoar, and with unknown psychiatric antecedents or follow-up.

Conclusions: A trichobezoar represents a serious surgical condition. It is important to consider such diagnosis in face of suggestive symptoms, even if signs of trichotillomania are not present. The discrepancies between the prevalence of trichotillomania and trichobezoars due to trichophagia may be due to issues related to self-selection of patients and symptom severity. Such issues may also be important in the study of impulsive-compulsive spectrum models and to their relevance to impulse control disorders.
\end{abstract}

Keywords: Trichobezoar, Rapunzel Syndrome, Trichotillomania, Trichophagia.

\section{INTRODUCTION}

Trichobezoars were first described by Baudomant in $1779[1,2]$, consisting of a compact mass of hair, occupying the gastric cavity to a various extent. The term "bezoar" is thought to be derived from the Arabic word for antidote "bazahr" or "badzehr", because stones obtained from the stomach or intestines of animals were thought to have medicinal properties [2-4].

Bezoars can be classified in four types: phytobezoar (vegetable); trichobezoar (hair); lactobezoar (milk/curd) and miscellaneous (fungus, sand, paper, etc) [5]. They are usually found in the stomach, but they may also be found in the duodenum and other parts of the intestine [3,6]. The most frequent type of bezoar in adults is phytobezoar, while trichobezoars are more often found in children and teenage girls [7]. The pathogenesis of bezoars is not consensual. It is believed that the smooth surface of hair does not allow for its propagation through peristalsis, getting trapped in the mucosa [7]. However, the stomach of normal individuals is able to clear even large foreign bodies in up to 80 to $90 \%$ of the

*Address correspondence to this author at the Department of Psychiatry and Mental Health, Hospital Infante D. Pedro Rua Artur Ravara 3810-AVEIRO Portugal; Tel: +351 93 6673106; Fax: 234378 395;

E-mail: tiagoazevsantos@gmail.com cases, which may imply that bezoar formation occurs in the presence of both altered gastric anatomy or physiology and continued ingestion of the offending substance $[8,9]$. When the trichobezoar is seen extending from the stomach to various lengths of the intestine is called "Rapunzel Syndrome", for its resemblance to a tail $[10,11]$.

Trichobezoars present with signs and symptoms of acute abdomen and gastric tract obstruction. These include abdominal pain, nausea, bilious vomiting, hematemesis, anorexia, early satiety, weakness, weight loss and abdominal mass, depending on the degree of obstruction [5, 10, 12]. The diagnosis of trichobezoars is based on imagiologic evidence. Ultrasonography is effective in detecting an epigastric mass, although CT-scan is more accurate in revealing a characteristic bezoar image and allowing the identification of the presence of additional gastrointestinal bezoars. The definite diagnosis is established by endoscopy $[5,8,13]$. Trichobezoars demand aggressive treatment, often implying surgical intervention, without which mortality rates may be high [3, $4,6]$.

Trichobezoars are usually described in the context of an underlying psychiatric disorder, trichotillomania in particular which is also implicitly taken as cause of it, and usually accompanied by characteristic features such as signs of alopecia [5-7, 11]. Although trichobezoars are well described in terms of surgical diagnosis and procedure, there are only but 


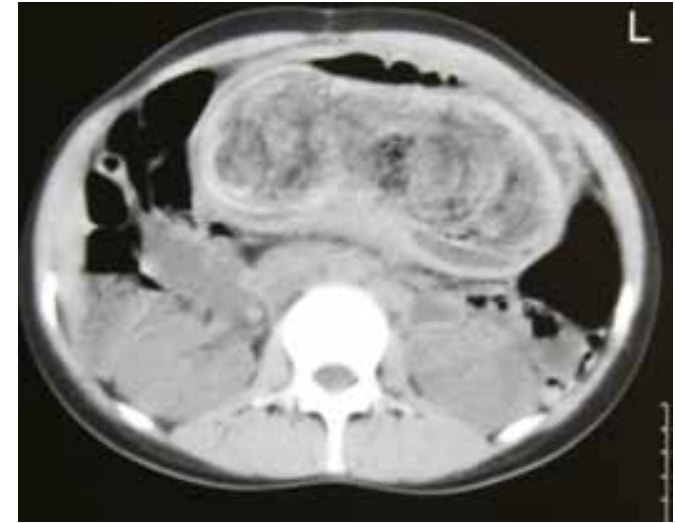

Fig. (1). CT-Scan prior to surgery.

scarce reports on psychiatric literature. This case report describes the case of a 27- year-old female patient diagnosed with a trichobezoar who had a previous similar diagnosis without any psychiatric evaluation or management.

\section{CASE REPORT}

A 27 year-old caucasian woman presented to the Emergency Department with bloating and weight loss for two months and recent episodes of epigastric pain, nausea and vomiting of increasing frequency and severity. Her physical examination revealed the presence of a large, hard, solid mass from epigastric to periumbilical region, mobile and painless with no other remarkable features. On further evaluation, a microcytic anemia was detected; an abdominal ultra-sound revealed a highly reflective structure not allowing in-depth evaluation, and a CT-scan reported a distended stomach, filled with heterogeneous density material, probably bezoar (Fig. 1). An upper endoscopy was eventually performed, confirming the presence of a trichobezoar occupying all gastric cavity. The patient had a previous history of a trichobezoar surgically removed in 2000, and no personal or family psychiatric history. The treatment consisted of an anterior gastrotomy with removal of bezoar and biopsy of existent gastric ulcer, which revealed the presence of human hair (Fig. 2).

\section{PERSONAL HISTORY AND FOLLOW-UP}

M. comes from a low income family of 8 brothers and sisters, and she is the second youngest. Her parents are small farmers, and all work in the family farm. None of them studied beyond primary school. Although poor, they are respected members of the community, a small village of a rural area. There is no known psychiatric history in the family.

M. was born at home, after a normal pregnancy. Although brought up like her brothers, M. revealed herself a student above average and didn't like working in the fields, a job she considered "too heavy and with no future". In spite of her relative success, M. dropped school at the age of 11, by her parents' decision and against her will. She worked on the farm and in a few random unqualified jobs.

At the age of 14, M. met her future husband, six years older, and three months later they decided to live together in his village nearby. M.'s family didn't approve their relationship, but she keeps up to her decision and left home, breaking the ties with her father and some of her brothers. M.'s

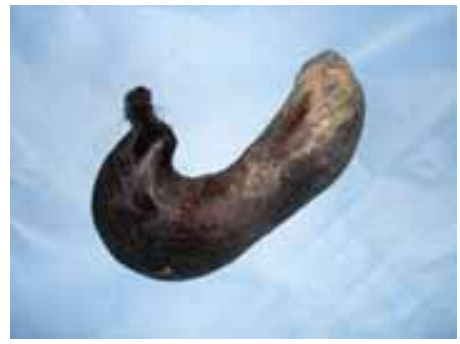

Fig. (2). Trichobezoar extracted.

wishes of continuing studying were supported by her husband; she graduated from junior high and took professional courses. They married when she was 17 and the couple moved next to her mother-in-law, who had a very dominant role in the family and over her husband. After a few months he immigrated and left Mary, pregnant, living with his mother, with whom she described having a "difficult and tense relation".

Two months after their first child is born, a first bezoar is detected and removed. M. didn't know how to explain to her husband or to the other family members, who "didn't make many questions". She kept living next to her mother-in-law while her husband was away. Four years later, her second son was born, and 4 years after that $M$. is again hospitalized for a second bezoar extraction, described in this case report.

During psychiatric follow-up, the patient always denied trichotillomania or trichotillophagia, revealing anxiety and shame regarding the subject. She showed no depressive or psychotic symptoms, suicidal ideation or other psychiatric symptoms besides episodic anxiety and initial insomnia; she mentioned that on those occasions, "I tend to become very nervous sometimes, and when that happens I can't remember many things I do...". The patient was medicated with fluoxetine $20 \mathrm{mg}$ and risperidone $0,5 \mathrm{mg}$, showing "mild improvement" in such episodes.

However, the follow-up was interrupted four weeks after the surgical discharge; the patient decided to move next to her husband without further notice, although several contacts were made to resume evaluation.

\section{DISCUSSION}

The case presented is one of the rare reports of trichobezoars in psychiatric literature. To the author's knowledge, only three similar cases have been reported $[3,7,11]$. On the contrary, surgeons and paediatricians have abundant descriptions of trichobezoar cases, suggesting that this condition is not uncommon. As Bouwer and Stein point out, it is also striking that trichophagia was described a century before trichotillomania, while an early case series of trichobezoars remains larger than most case series of trichotillomania patients [3, 6, 13-15].

Trichobezoars are usually associated to underlying psychiatric disorders, such as depression, obsessive-compulsive disorder, body dysmorphic disorder and, particularly, trichotillomania $[5,8,10]$. However, their prevalence and co-morbidity is unclear. Depending on the case series, 5 to $30 \%$ of the patients with trichotillomania engage in trichophagia $[3,7,11]$, while 1 to $37,5 \%$ of these will develop a trichobezoar $[3,11,16,17]$. 
An explanation for such disparities may be the fact that most trichotillomania patients are referred to psychiatry units by their own initiative, possibly limiting the physical consequences of their disorder [3], while trichobezoar patients are usually referred in a late stage to surgery units. On the other hand, these patients may not be identified by clinicians as having a psychiatric problem, or they may simply be lost in psychiatric referral after surgical recovery. This was the case of the patient described, who never recognized engaging in trichotillomania or trichophagia, and didn't have any signs which could suggest such behaviour. It is reasonable to assume that the degree of shame or guilt was enough for the patient to abandon the psychiatric treatment after a short period.

The case described also challenges the usual concept of impulsivity versus compulsivity. It is not clear whether the patient would engage in trichophagia as an impulsive condition, more related to trichotillomania, or closer to OCD phenomenology, despite the current discussion over the validity of such diagnostic classifications [18-20].

According to a vulnerability-stress model, it is pertinent to assume that the patient's premorbid personality traits, such as consciousness, perfectionism and introversion, interacted with a constellation of stressing life-events in a systemic fashion. M.'s ambitions diverge from what her social and familiar background expects from her; she found a supporting partner, but at the cost of disrupting the relation with her family. Her new environment is not protective and her husband, her safety reference, went abroad. M. is not confident in her boundaries and avoids conflicts at any cost, getting caught in a dilemma: staying with her husband's family or returning home and facing overt criticism and hostility. The authors assume that these factors combined induced a degree of distress which triggered the clinical picture. Interestingly, during the short psychiatric follow-up, no member of both families was available for an interview, nor the patient expressed comfort regarding such possibility.

Considering the ego-dystonic nature of the behaviour revealed by the denial and shame, along with the stereotypic nature of the trichophagia behaviour, the authors tend to an obsessive-compulsive background, in spite of affirming the interest in recent proposals of models of impulsivecompulsive spectrum $[19,20]$.

The early detection of trichophagia and trichobezoar depends on an effective screening for trichotillomania and related behaviours, in order to prevent a possibly lifethreatening condition with important medical and surgical morbidity. Such effort must include a better collaboration between medical and surgical specialties, dealing with particular aspects of therapeutic relationship regarding shame and guilt as well as considering that trichophagia may be more often present than the majority of clinicians, psychiatrists in particular, would expect.

\section{LIST OF ABBREVIATIONS}

None.

\section{CONFLICT OF INTEREST}

None.

\section{ACKNOWLEDGEMENTS}

None.

\section{REFERENCES}

[1] Malpani A, Ramani SK, Wolverson MK. Role of sonography in trichobezoars. J Ultrasound Med 1988; 7: 661-3.

[2] Shorter E. A historical dictionary of psychiatry. Oxford University Press: New York. 2005.

[3] Bouwer C, Stein DJ. Trichobezoars in trichotillomania: Case report and literature overview. Psychosom Med 1998; 60: 658-60.

[4] Williams RS. The fascinating history of bezoars. Med J Aust 1986; 145: 613-4.

[5] Sehgal VN, Srivastava G. Trichotillomania \pm trichobezoar: revisited. Eur Acad Dermatol Venereol 2006; 20: 911-5.

[6] DeBakey M, Ochsner W. Bezoars and concretions: A comprehensive review of the literature with an analysis of 303 collected cases and a presentation of 8 additional cases. Surgery 1939; 5: 132-60.

[7] Frey AS, McKee M, King RA, Martin A. Hair apparent: Rapunzel syndrome. Am J Psychiatry 2005; 162: 2.

[8] Coulter R, Antony MT, Bhuta P, Memon MA. Large gastric trichobezoar in a normal healthy woman: Case report and review of pertinent literature. Southern Med J 2005; 98: 10.

[9] Lee J. Bezoars and foreign bodies of the stomach. Gastrointest Endosc Clin N Am 1996; 6: 605-19.

[10] Pérez E, Sántana JR, García G, et al. Perforación gástrica en adulto por tricobezoar (síndrome de Rapunzel). Cir Esp 2005; 78(4): 268-70.

[11] Salaam K, Carr J, Grewal H, Sholevar E, Baron D. Untreated trichotillomania and trichophagia: Surgical emergency in a teenage girl. Psychosomatics 2005; 46: 4.

[12] Deslypere JP, Praet M, Verdonk G. An unusual case of the trichobezoar: The Rapunzel syndrome. Am J Gastroenterol 1982; 77: 467-70.

[13] Carr JR, Sholevar EH, Baron DA. Trichotillomania and trichobezoar: A clinical practice insight with report of illustrative case. J Am Osteopath Assoc 2006; 106: 647-52.

[14] Vaughan ED, Sawyers JL, Scott HW. The Rapunzel syndrome: An unusual complication of intestinal bezoar. Surgery 1968; 63: 33943.

[15] American Psychiatric Association. Diagnostic and Statistical Manual of Mental Disorders. APA, Washington DC. 1994; $4^{\text {th }}$ ed.

[16] Christenson GA, MacKenzie TB, Mitchell JE. Characteristics of 60 adult chronic hair pullers. Am J Psychiatry 1991; 148: 365-70.

[17] Christenson GA, Crow SJ. The characterization and treatment of trichotillomania. Clin Psychiatry 1996; 57(suppl 8): $42-7$.

[18] Stein DJ, Muller L, Islam MN, Cohen L, DeCaria CM, Hollander E. Compulsive and impulsive symptomatology in trichotillomania. Psychopathology 1995; 28: 208-13.

[19] Hollander E, Kim S, Khanna S, Pallanti S. Obsessive-compulsive disorder and obsessive-compulsive spectrum disorders: diagnostic and dimensional issues. CNS Spectr 2007; 2(suppl 3): 12.

[20] Grant JE, Potenza MN. Compulsive aspects of impulse-control disorders. Psychiatr Clin North Am 2006; 29(2): 539-x. 